\title{
Analysis of Canadian and Irish forage, oats and commercially available equine concentrate feed for pathogenic fungi and mycotoxins
}

\author{
Thomas Buckley, Alan Creighton, Ursula Fogarty \\ Irish Equine Centre, Johnstown, Naas, Co. Kildare, Ireland \\ Corresponding author: \\ Thomas Buckley, Irish Equine Centre, Johnstown, Naas, Co. Kildare, Ireland \\ Email: tbuckley@equine-centre.ie \\ Tel: $\quad$ +35345866266 \\ Fax: $\quad+35345866701$
}

Respiratory infections, recurrent airway obstruction (RAO) and exercise induced pulmonary haemorrhage (EIPH) are major causes of poor performance in horses. Fungi and mycotoxins are now recognised as a major cause of these conditions. The most notable fungi are Aspergillus and Fusarium. Fungal spores can originate from forage, bedding and feed and, in turn, these fungal spores can produce a series of mycotoxins as secondary metabolites.

This study set out to ascertain the degree of fungal and mycotoxin contamination in feed and fodder used in Irish racing yards over a oneyear period. Weather conditions in forage producing areas were sampled by Met Eireann and the Canadian Meteorological Service. Fifty per cent of Irish hay, $37 \%$ of haylage and $13 \%$ of Canadian hay contained pathogenic fungi. Of the mycotoxins, T2 and zearalenone were most prominent. Twenty-one per cent of Irish hay and $16 \%$ of pelleted feed contained zearalenone. Forty per cent of oats and $54 \%$ of pelleted feed contained T2 toxins.

Key words: Aspergillus, mycotoxins, RAO, EIPH

Irish Veterinary Journal Volume 60 Number 4, 231-236, 2007

\section{Introduction}

There are two main groups of fungi for concern in the equine world. They are the field fungus Fusarium, which produces the toxins fumonisin, zearalenone and $\mathrm{T} 2$, and the storage fungus Aspergillus, which produces the toxins aflatoxin and ochratoxin. Aspergillus is a toxigenic fungus which is ubiquitous in nature. Many species are identified, yet there are only three implicated in disease: Aspergillus fumigatus; Aspergillus niger; and Aspergillus flavus. The other important toxigenic fungus, in relation to disease in horses, is Fusarium because it is a potent producer of mycotoxins. Animals affected by mycotoxins may display symptoms such as digestive disorders, reduced feed consumption, poor thrift, impaired immunity, impaired reproduction and an undernourished appearance. They are not transmissible from animal to animal but are associated with consumption of infected feeds and forages (Quinn et al., 2002). Several toxins have been linked with increased incidences of cancer in humans, notably aflatoxin, fumonisin, zearalenone and ochratoxin (Jacobsen et al., 1999). Aflatoxin is a carcinogenic liver toxin which can suppress immunity and cause inappetance and ataxia. Fumonisins are carcinogenic to all animals and have long been associated with leucoencephalomalacia, a sporadic neurological disease in horses (Smith et al., 1997). Ochratoxins and T2 toxin both interfere with protein synthesis and affect immune responses by suppressing antibody formation.
A performance horse is an athlete which cannot realise its full potential if its respiratory system is not functioning to the best of its ability. During peak performance, the racing Thoroughbred will inhale and exhale up to 15 litres of air in each of 150 breaths per minute, a total of over 2,000 litres per minute (Clarke, 2001). The ability of the airways to meet those massive demands can be compromised by inflammatory and/or allergic reactions induced by infectious agents, toxins, dust, or noxious gases. Recently, there has been growing recognition that some fungi, most notably Aspergillus and Fusarium species and their mycotoxins, exert seriously deleterious effects on the performance of the equine athlete (Clarke, 2001). Recurrent airway obstruction (RAO) is an allergic response which is comparable to asthma in humans. Fungal spores, which can originate from hay, bedding and feed, are the most common cause of RAO and can also cause exercise induced pulmonary haemorrhage (EIPH), also known as bleeding (Quinn et al., 2002). Under certain conditions, fungal moulds grow unnoticed and can produce mycotoxins, toxic secondary metabolites. Mycotoxins are produced by fungi which can grow in baled hay, stored grain or silage with a high moisture content (Murphy, 1991) and it has been estimated that $25 \%$ of the world's crop production is contaminated with mycotoxins (Smith et al., 1994; Smith et al., 1997). These toxins can produce diseases known as mycotoxicosis and 
the symptoms of such diseases vary greatly. Mycotoxin effects are species specific and produce distinctly different symptoms in various animals (Osweiler, 1996). These can include digestive disorders, reduced feed consumption, general poor thrift, an undernourished appearance, immune suppression, subnormal production, impaired reproduction and/or a mixed, infectious disease profile (Whitlow and Haglar, 2002). In livestock, the five leading mycotoxins present in feed that impair growth and disrupt reproduction are aflatoxin, zearalenone, fumonisin, T2 and ochratoxin (Diekman et al., 1992). In pigs, mycotoxins impair liver and kidney function and delay blood clotting and immune responses. Even limited exposure of Fusarium mycotoxins to pregnant swine can result in embryonic loss and disruption of normal reproductive cycling for an extended period of time (Long et al., 1983). Mycotoxins may cause similar symptoms in horses as in other animals and, currently, research into the effects of mycotoxins in this species is ongoing. At present, literature points towards mould being one of the main factors in respiratory disease in horses both by ingestion and inhalation. In time, we hope to show, through research, that ingested mycotoxins may also play a negative role in the respiratory system.

In this study, samples of hay, haylage, oats and concentrate feed were taken at intervals over a one-year period and used to estimate the possible exposure of horses to moulds and their mycotoxins. Weather data for the two harvesting periods in which the feedstuffs were produced were examined to ascertain if there was an obvious relationship with the prevalence of mould in the samples.

\section{Materials and methods Sampling techniques}

All of the samples tested were taken over a one-year period from October 1, 2002 to September 30, 2003, from equine racing yards in Leinster and Munster with horses in training. All of the Irish forage samples had been produced in the two provinces. The Canadian forage was produced in Calgary and Lethbridge.

All forage samples were taken from the centre of bales. Approximately $100 \mathrm{~g}$ of fodder was collected by taking $20 \mathrm{~g}$ aliquots from five different bales, from different areas of the fodder stack. The five aliquots were pooled and placed in a sterile plastic bag which was sealed. Sterile gloves were worn at all times and they were changed between samples.

All concentrate feed samples were taken from the centre of sealed bags. Approximately $100 \mathrm{~g}$ of feed was collected by taking $20 \mathrm{~g}$ aliquots from five different bags. The five aliquots were pooled and placed in a sterile plastic bag which was sealed. Sterile gloves were worn at all times and changed between samples.

All of the feed/fodder samples were ground using a centrifugal ultra mill (Retsch ZM100, Germany). The screen size was $1 \mathrm{~mm}$ and the pre-selected speed ' $\mathrm{K}$ ' was selected at 14,000 rpm. The appropriate grinding tool was inserted depending on the type of sample. A six-tooth rotor was used for fodders and nuts and a 12tooth rotor was used for oats and coarse mixes. When the entire sample was loaded, the apparatus was allowed to run for one minute. The sample was then removed aseptically and placed in a $150 \mathrm{ml}$ container. The mill was sterilised between samples using Equisept disinfectant (Thoroughbred Remedies Ireland, Co.Kildare) at a concentration of $1400 \mathrm{ppm}$. The samples were stored at between $1^{\circ} \mathrm{C}$ and $4^{\circ} \mathrm{C}$ until extraction and analysis.

\section{Sample extraction}

As several mycotoxins were being tested for, several different extraction protocols were employed (Table 1).

\section{Extraction protocol 1}

This protocol was used on samples being analysed for aflatoxin-HS, total aflatoxin and zearalenone. The sample material was ground as fine as possible in a food blender. Five grammes of the sample material was added to a $100 \mathrm{ml}$ screw cap pot. Each pot was labelled with the unique NEOGEN sample code. Twenty-five millilitres of $70 \%$ methanol were added to each pot. The pot was shaken vigorously for three minutes. The sample material was allowed to settle for two to three minutes. The extract was poured into a sterile $1.5 \mathrm{ml}$ eppendorf until it was almost full. Each tube was labelled with the unique NEOGEN sample code, as allocated earlier. The tube was spun in the micro-centrifuge for three minutes at $10,000 \mathrm{rpm}$. The sample extract was then ready for testing.

\section{Extraction protocol 2}

Protocol 2 was identical to protocol 1 except that $25 \mathrm{ml}$ of distilled water, instead of the $25 \mathrm{ml}$ of $70 \%$ methanol, was added.

\section{Extraction protocol 3}

Protocol 3 was identical to protocol 1 except for two changes: $10 \mathrm{~g}$, instead of $5 \mathrm{~g}$, of sample was used and $40 \mathrm{ml}$ of $50 \%$ methanol, instead of $25 \mathrm{ml}$ of $70 \%$ methanol, was added.

\section{Extraction protocol 4}

Protocol 4 was identical to protocol 1, except for one change: $25 \mathrm{ml}$ of $50 \%$ methanol, instead of $25 \mathrm{ml}$ of $70 \%$ methanol, was added.

Table 1: Extraction protocols used

\begin{tabular}{|l|l|l|l|l|l|l|}
\hline Sample type & Aflatoxin & Ochratoxin & Vomitoxin & Zearalenone & T2 & Fumonisin \\
\hline Oats & 1 & 3 & 2 & 1 & 4 & 5 \\
\hline Hay/silage & 1 & 3 & 2 & 1 & 4 & 5 \\
\hline Coarse mix & 1 & 3 & 2 & 1 & 4 & 5 \\
\hline Cubes & 1 & 3 & 2 & 1 & 4 & 5
\end{tabular}


Table 2: Forage harvest climate statistics during 2002 and a 30-year period (1961-1990) for Leinster and Munster obtained from Met Eireann and Canadian Meteorological Service

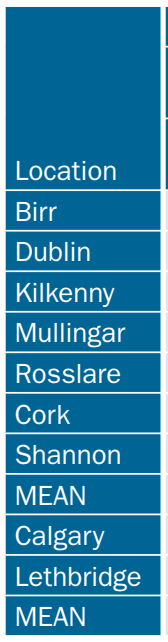

\begin{tabular}{|r|l|l|l|l|l|}
\hline \multicolumn{3}{|l|}{ May } \\
\hline \multicolumn{2}{|l|}{ Rainfall $(\mathrm{mm})$} & \multicolumn{2}{l|}{$\begin{array}{l}\text { Mean temp. } \\
\left({ }^{\circ} \mathrm{C}\right)\end{array}$} & \multicolumn{2}{l|}{$\begin{array}{l}\text { Rel. humidity } \\
(\%)\end{array}$} \\
\hline 2002 & $\begin{array}{l}30 \mathrm{Yr} \\
\text { Mean }\end{array}$ & 2002 & $\begin{array}{l}30 \mathrm{Yr} \\
\text { Mean }\end{array}$ & 2002 & $\begin{array}{l}30 \mathrm{Yr} \\
\text { Mean }\end{array}$ \\
\hline 109.6 & 61.7 & 15.8 & 14.9 & 68.0 & 64.0 \\
\hline 121.3 & 55.1 & 14.1 & 14.2 & 72.0 & 67.0 \\
\hline 105.4 & 61.9 & 14.8 & 15.1 & 69.0 & 64.0 \\
\hline 117.6 & 72.4 & 15.2 & 14.7 & 68.0 & 68.0 \\
\hline 89.1 & 55.5 & 14.1 & 13.2 & 79.0 & 77.0 \\
\hline 162.8 & 83.4 & 14.8 & 13.8 & 74.0 & 71.0 \\
\hline 139.6 & 60.1 & 15.9 & 15.3 & 68.0 & 64.0 \\
\hline 120.8 & 64.3 & 14.9 & 14.5 & 71.1 & 67.9 \\
\hline 10.9 & 51.4 & 12.9 & 16.4 & 40.6 & 42.8 \\
\hline 31.5 & 49.4 & 15.1 & 18.2 & 39.8 & 40.3 \\
\hline 21.2 & 50.4 & 14.0 & 17.3 & 40.2 & 41.7 \\
\hline & & & & & \\
\hline
\end{tabular}

\begin{tabular}{|r|l|l|l|l|l|}
\hline \multicolumn{3}{|l|}{ June } \\
\multicolumn{3}{|c|}{ Rainfall $(\mathrm{mm})$} & \multicolumn{2}{l|}{$\begin{array}{l}\text { Mean temp. } \\
\left({ }^{\circ} \mathrm{C}\right)\end{array}$} & \multicolumn{2}{l|}{$\begin{array}{l}\text { Rel.humidity } \\
(\%)\end{array}$} \\
\hline 2002 & $\begin{array}{l}30 \mathrm{Yr} \\
\text { Mean }\end{array}$ & 2002 & $\begin{array}{l}30 \mathrm{Yr} \\
\text { Mean }\end{array}$ & 2002 & $\begin{array}{l}30 \mathrm{Yr} \\
\text { Mean }\end{array}$ \\
\hline 96.2 & 55.2 & 18.8 & 17.7 & 71.0 & 66.0 \\
\hline 81.2 & 56.0 & 17.4 & 17.2 & 73.0 & 68.0 \\
\hline 80.4 & 50.5 & 17.7 & 18.1 & 69.0 & 65.0 \\
\hline 89.6 & 66.2 & 17.1 & 17.5 & 81.0 & 79.0 \\
\hline 49.8 & 47.6 & 16.4 & 15.9 & 82.0 & 78.0 \\
\hline 105.2 & 68.8 & 17.7 & 16.6 & 77.0 & 72.0 \\
\hline 89.8 & 62.4 & 18.2 & 17.9 & 71.0 & 67.0 \\
\hline 84.6 & 58.1 & 17.6 & 17.3 & 75.0 & 71.0 \\
\hline 58.6 & 79.8 & 21.3 & 20.2 & 46.0 & 45.8 \\
\hline 25.1 & 63.0 & 21.5 & 22.3 & 40.8 & 41.4 \\
\hline 41.9 & 71.3 & 21.4 & 21.3 & 43.4 & 43.6 \\
\hline
\end{tabular}

\begin{tabular}{|l|l|l|l|l|l|}
\hline \multicolumn{3}{|l|}{ July } \\
\multicolumn{3}{|l|}{ Rainfall $(\mathrm{mm})$} & $\begin{array}{l}\text { Mean temp } \\
\left({ }^{\circ} \mathrm{C}\right)\end{array}$ & \multicolumn{2}{l|}{$\begin{array}{l}\text { Rel.humidity } \\
(\%)\end{array}$} \\
\hline 2002 & $\begin{array}{l}30 \mathrm{Yr} \\
\text { Mean }\end{array}$ & 2002 & $\begin{array}{l}30 \mathrm{Yr} \\
\text { Mean }\end{array}$ & 2002 & $\begin{array}{l}30 \mathrm{Yr} \\
\text { Mean }\end{array}$ \\
\hline 68.2 & 59.1 & 20.1 & 19.2 & 69.0 & 67.0 \\
\hline 68.9 & 49.9 & 19.4 & 18.9 & 71.0 & 68.0 \\
\hline 74.4 & 52.5 & 19.4 & 19.9 & 69.0 & 65.0 \\
\hline 81.3 & 61.8 & 18.9 & 19.0 & 74.0 & 70.0 \\
\hline 36.0 & 50.7 & 18.1 & 17.9 & 76.0 & 77.0 \\
\hline 54.0 & 66.4 & 17.7 & 18.5 & 76.0 & 72.0 \\
\hline 68.1 & 57.1 & 18.9 & 19.4 & 71.0 & 68.0 \\
\hline 64.4 & 56.8 & 18.9 & 19.0 & 72.3 & 69.6 \\
\hline 34.6 & 67.9 & 26.1 & 22.9 & 42.4 & 45.7 \\
\hline 34.0 & 47.5 & 27.3 & 25.5 & 40.6 & 39.9 \\
\hline 34.3 & 57.7 & 26.7 & 24.2 & 41.5 & 42.8 \\
\hline
\end{tabular}

Extraction protocol 5

Protocol 5 was identical to protocol 1 except for one change: $100 \mu$ of the sample was extracted to a sample dilution bottle and mixed as per manufacturer's per manufacturer's (Neogen Corporation, Nellies Gate, Ayr, Scotland) instructions.

\section{ELISA procedure}

ELISA testing was carried out as per manufacturer's (Neogen Corporation, Nellies Gate, Ayr, Scotland) instructions.

\section{Culture techniques and identification}

Ten grammes of each sample was added to $90 \mathrm{ml}$ of sterile distilled water in a labelled $150 \mathrm{ml}$ container. The containers were then placed on a shaker for ten minutes. One millilitre of each of the samples was then pipetted onto a correspondingly labelled Sabouraud dextrose agar plate (Oxoid, Basingstoke). Using a spreader, the solution was spread evenly over the plates. The plates were then incubated at $25^{\circ} \mathrm{C}$ for five days. After incubation, all plates were examined for fungal growth using conventional methods. The cultures were examined using the sellotape method. A loop was made with a length of sellotape. The base of the loop was touched gently onto the fungal culture so that some of the mycelium adhered to the tape. A drop of lactophenol cotton blue was placed on a microscope slide. The sellotape was placed on top of the stain and pressed down lightly. The slide was then examined under X10 and X40 magnification. The different species of fungi were characterised by colonial morphology and microscopy.

On culture, typical colonies were counted and noted. The cultures are a result of an earlier $1 / 10$ dilution. It was decided to group the growths of fungi into light, moderate and heavy growths:

Light growth $=1-6$ typical colonies $=10-60 \mathrm{cfu} / \mathrm{g}$ of sample Medium growth $=7-12$ typical colonies $=70-120 \mathrm{cfu} / \mathrm{g}$ of sample Heavy growth $=$ over 12 typical colonies $=>120 \mathrm{cfu} / \mathrm{g}$ of sample cfu: colony forming unit

Table 3: Cereal harvest climate statistics during 2002 and a 30-year period (1961-1990) for Leinster and Munster obtained from Met Eireann and Canadian Meteorological Service
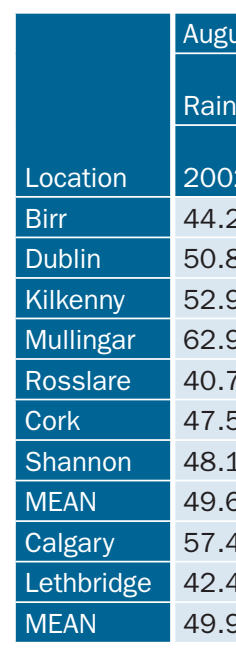

\begin{tabular}{|l|}
\hline August \\
\hline Rainfall \\
\hline 2002 \\
\hline 44.2 \\
\hline 50.8 \\
\hline 52.9 \\
\hline 62.9 \\
40.7 \\
\hline 47.5 \\
48.1 \\
\hline 49.6 \\
\hline 57.4 \\
\hline 42.4 \\
49.9 \\
\hline
\end{tabular}

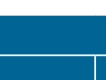

Mean temp

\begin{tabular}{l|l}
$30 \mathrm{Yr}$ & $\left({ }^{\circ} \mathrm{C}\right)$ \\
\hline
\end{tabular}

Mean

77.6

2002

$30 \mathrm{Yr}$
Mean

Rel.

Rel.humidity (\%)

68.068 .0

\begin{tabular}{|l|l|l|l|l|}
\hline & 18.1 & 18.6 & 71.0 & 70.0 \\
\hline
\end{tabular}

\begin{tabular}{|l|l|l|l|l|}
69.4 & 19.4 & 19.6 & 64.0 & 66.0
\end{tabular}

\begin{tabular}{|l|l|l|l|l|}
81.2 & 18.6 & 18.6 & 60.0 & 72.0 \\
\hline
\end{tabular}

\begin{tabular}{|l|l|l|l|l|}
68.7 & 17.7 & 17.9 & 75.0 & 78.0
\end{tabular}

\begin{tabular}{|l|l|l|l|l|}
88.7 & 18.0 & 18.2 & 73.0 & 73.0 \\
\hline
\end{tabular}

\begin{tabular}{|l|l|l|l|l|}
82.3 & 18.7 & 19.2 & 67.0 & 69.0 \\
\hline
\end{tabular}

\begin{tabular}{|l|l|l|l|l|}
76.9 & 18.4 & 18.7 & 70.0 & 71.0 \\
\hline
\end{tabular}

\begin{tabular}{|l|l|l|l|l|}
58.7 & 21.1 & 22.5 & 44.6 & 44.8 \\
\hline
\end{tabular}

\begin{tabular}{|l|l|l|l|l|}
\hline 45.1 & 22.0 & 25.4 & 56.5 & 56.8
\end{tabular}

\begin{tabular}{|l|l|l|l|l|}
51.9 & 21.5 & 24.0 & 51.0 & 50.8 \\
\hline
\end{tabular}

\begin{tabular}{|c|c|c|c|c|c|}
\hline \multicolumn{6}{|c|}{ September } \\
\hline \multicolumn{2}{|c|}{ Rainfall (mm) } & \multicolumn{2}{|c|}{ Mean temp $\left({ }^{\circ} \mathrm{C}\right)$} & \multicolumn{2}{|c|}{$\begin{array}{l}\text { Rel.humidity } \\
\text { (\%) }\end{array}$} \\
\hline 2002 & $\begin{array}{l}30 \mathrm{Yr} \\
\text { Mean }\end{array}$ & 2002 & $\begin{array}{l}30 \mathrm{Yr} \\
\text { Mean }\end{array}$ & 2002 & $\begin{array}{l}30 \mathrm{Yr} \\
\text { Mean }\end{array}$ \\
\hline 22.6 & 70.6 & 16.0 & 16.6 & 71.0 & 72.0 \\
\hline 22.6 & 66.7 & 16.9 & 16.6 & 69.0 & 70.0 \\
\hline 19.7 & 73.5 & 17.4 & 17.2 & 68.0 & 69.0 \\
\hline 18.9 & 85.9 & 16.7 & 16.4 & 71.0 & 74.0 \\
\hline 12.4 & 73.3 & 16.4 & 16.3 & 76.0 & 76.0 \\
\hline 35.6 & 96.4 & 16.4 & 16.0 & 72.0 & 76.0 \\
\hline 19.4 & 81.8 & 17.5 & 17.2 & 68.0 & 71.0 \\
\hline 21.6 & 78.3 & 16.8 & 16.6 & 71.0 & 73.0 \\
\hline 54.0 & 41.7 & 16.4 & 17.6 & 45.0 & 45.1 \\
\hline 48.3 & 37.6 & 18.8 & 20.1 & 52.9 & 53.1 \\
\hline 51.0 & 39.7 & 17.6 & 18.0 & 49.0 & 49.1 \\
\hline
\end{tabular}


Table 4: Pathogenic fungi isolated from forage/feed during the period October 1, 2002 and September 30, 2003.

\begin{tabular}{|c|c|c|c|c|c|c|c|}
\hline \multirow[b]{2}{*}{ Fodder type } & \multirow{2}{*}{$\begin{array}{l}\text { Number } \\
\text { sampled }\end{array}$} & \multicolumn{2}{|c|}{$\begin{array}{l}\text { Pathogenic fungi } \\
\text { isolated }\end{array}$} & \multirow{2}{*}{$\begin{array}{l}\text { Number } A \text {. } \\
\text { fumigatus }\end{array}$} & \multirow{2}{*}{$\begin{array}{l}\text { Number } \\
\text { A. niger }\end{array}$} & \multirow{2}{*}{$\begin{array}{l}\text { Number } \\
\text { A. flavus }\end{array}$} & \multirow{2}{*}{$\begin{array}{l}\text { Number } \\
\text { Fusarium }\end{array}$} \\
\hline & & No. & $\%$ & & & & \\
\hline Canadian hay & 63 & 8 & 13 & 4 & 4 & 2 & 0 \\
\hline Irish hay & 62 & 31 & 50 & 9 & 11 & 11 & 0 \\
\hline Haylage & 54 & 20 & 37 & 16 & 2 & 2 & 0 \\
\hline Coarse mix & 38 & 5 & 13 & 0 & 2 & 2 & 1 \\
\hline Oats & 26 & 2 & 8 & 0 & 1 & 1 & 0 \\
\hline Pelleted feed & 51 & 2 & 4 & 0 & 0 & 2 & 0 \\
\hline
\end{tabular}

\section{Meteorological data}

Harvesting of forage, in the northern hemisphere, occurs predominantly in the months of May to July. Harvesting of grain crops occurs during the months of August to September. Five to seven days of good dry weather is required for haymakers. Haylage requires three to four days whereas grain harvest requires dry conditions at harvest time.

Monthly data reports of total rainfall, relative humidity and temperature for those months in 2002 were obtained from the Met Eireann and the Canadian Meteorological Service stations of the regions which the forage and crops were produced. Weather and crop reports were also obtained from Teagasc, the Irish farm advisory service, for haymaking.

\section{Results}

Tables 2 to 5 show the results obtained in the study. Note that any species of non-pathogenic fungi that were isolated (e.g., Mucor and most Penicillium sp) were not included in the results.

For each of the three months of the forage harvest period (May, June and July of 2002), data from seven weather stations in Leinster/Munster and two from Canadian areas, where the sampled forage was produced, were used to derive mean weather statistics (Table 2). The most striking observation is the increase in rainfall and relative humidity in 2002 compared to the 30-year mean for the Irish weather stations. During the same period in Canada, there was an overall reduction.

The results of Table 3 show the climatic conditions from seven meteorological stations in Ireland and the two Canadian stations in August and September, detailing the rainfall, temperature and the relative humidity.

Table 4 shows the number of samples tested during the period of October 1, 2002 to September 30, 2003, including those that tested postive for pathogenic fungi. A greater percentage of Irish hay and haylage samples tested positive than the Canadian hay samples. The amount of pathogenic fungi isolated from the feed samples, i.e., oats, coarse mix and pellets, was significantly lower than in fodder. Aspergillus fumigatus was isolated on 16 occasions from haylage. Fusarium, the field fungus, was not isolated from any of the fodder samples and only once in a feed sample.

Table 5 shows the distribution of five mycotoxins in feed and forage: the number sampled, the number above the recommended level; and, the percentage above the recommended levels. The recommended levels are based on FDA (US Food and Drug Administration) and EU advisory levels for mycotoxins in horses and are as follows:

- Aflatoxin - 50 ppb (legislation)

- Zearalenone - 150 ppb (recommended)

- Fumonisin - 50 ppm (recommended by FDA)

- Ochratoxin - $20 \mathrm{ppb}$ (recommended)

- T2 toxin - 150 ppb (recommended)

Aflatoxin, as seen from the data, was not an issue in the tested season. The same cannot be said for ochratoxin and fumonisin, except for the coarse mix samples which had a small number of positives. All of the feed types, apart from oats, contained positives for zearalenone with the Irish hay being the most significant. None of the forage samples contained T 2 toxins but $14 \%$ of the coarse mix, $40 \%$ of the

Table 5: Mycotoxin results for forage and concentrates

\begin{tabular}{l|}
\hline Fodder type \\
\hline Irish hay \\
\hline Haylage \\
\hline Canadian hay \\
\hline Coarse mix \\
\hline Oats \\
\hline Pelleted feed \\
\hline
\end{tabular}

\begin{tabular}{|l|l|l|l|l|l|l|l|l|l|l|}
\hline \multicolumn{2}{|l|}{ Zearalenone } & \multicolumn{2}{|l|}{ Ochratoxin } & \multicolumn{2}{|l|}{ Aflatoxin } & \multicolumn{2}{|l|}{ T2 Toxin } & \multicolumn{2}{|l|}{ Fumonisin } \\
\hline No. & $\%$ & No. & $\%$ & No. & $\%$ & No. & P $(\%)$ & \multicolumn{2}{|l|}{ No. } & $\%$ \\
\hline 44 & $9(21)$ & 15 & $0(0)$ & 44 & $0(0)$ & 15 & $0(0)$ & 15 & $0(0)$ \\
\hline 40 & $3(8)$ & 34 & $0(0)$ & 40 & $0(0)$ & 34 & $0(0)$ & 34 & $0(0)$ \\
\hline 65 & $5(8)$ & 0 & $0(0)$ & 65 & $0(0)$ & 0 & $0(0)$ & 0 & $0(0)$ \\
\hline 35 & $2(6)$ & 28 & $1(4)$ & 35 & $0(0)$ & 28 & $4(14)$ & 31 & $2(6)$ \\
\hline 25 & $0(0)$ & 16 & $0(0)$ & 24 & $0(0)$ & 17 & $7(40)$ & 17 & $0(0)$ \\
\hline 50 & $8(16)$ & 50 & $0(0)$ & 50 & $0(0)$ & 50 & $27(54)$ & 50 & $0(0)$ \\
\hline
\end{tabular}

No. $=$ number positive $\%=\%$ positive 
oats and $50 \%$ of pelleted feed samples tested contained T2 toxins above the advisory or recommended levels.

\section{Discussion}

Fungal spores are the most common cause of RAO (Clarke, 2001). They can also contribute to EIPH, also known as 'bleeding'. Spores are highly antigenic and cause much damage to humans and animals if inhaled or ingested. Fungi also produce mycotoxins which are toxic secondary metabolites. They are produced during the secondary sporulation stage in response to a stressful situation and so are like a defence mechanism for the fungi (Clarke, 2001). Zearalenone is an oestrogenic toxin that can lead to reproductive problems and also cause anorexia, diarrhoea and dehydration (Smith et al., 1997).

The fungal spores which affect horses predominantly originate from feed and fodder. It has been estimated that $25 \%$ of the world's crop production is contaminated with mycotoxins (European Commission Services, 1994). Ireland's temperate climate can often present difficulties when it comes to providing suitable feed and fodder for horses. Problems arise during the production of hay as dry weather is required to reduce moisture content to $15-20 \%$. Haylage, however, only needs two days to wilt the grass before it is wrapped to preserve. For cereals, the weather at harvest time needs to be dry in order to reduce the moisture content to sufficiently inhibit mould growth. Toxigenic mould spores can proliferate when hay is baled damp, as can happen during a summer with a large volume of rain. If hay heats, Aspergillus fumigatus can often be found. Haylage may require less suitable weather but can also have problems. Producers often attempt to make hay, fail and then wrap it and call it haylage. This is unsuitable as little respiration will take place, aerobic conditions may exist and moulds will grow. Once haylage is produced, care has to be taken not to puncture the plastic that would allow both moisture and air to enter, which will encourage fungal growth. Unlike hay, once haylage is opened it has to be used within seventy-two hours or, again, fungi will proliferate.

It has been identified that wet, humid weather at flowering promotes infection by Fusarium of grain and grasses (Whitlow and Hagler, 2002). Fusarium is a field fungus and it has been shown that, whilst growing on grain, it can be inhibited and overgrown by Aspergillus during storage (Smith et al., 1997). Storage of feed and fodder is critical. High moisture and relative humidity can lead to an explosion of mould growth. Concentrated feeds are predominantly made from grains, they have their advantages but each ingredient is capable of contributing to the overall fungal and mycotoxin load. The increasing price of soya has led to some companies using citrus pulp and pine kernels instead, which may account for increased mycotoxin production. The varying stresses of heating and drying during processing of concentrates may encourage fungal damage and mycotoxin release. The competition for nutrients between fungi from harvest to storage may result in enough stresses for one or both to produce mycotoxins. There may also be a synergistic effect whereby products and toxins produced by one fungi may aid the propagation of another.

However, moisture is the undeniably important factor when discussing quality feed production for horses. Dry weather at harvest is critical in attempts to limit fungal growth and subsequent mycotoxin production. In 2002, the mean rainfall for the five weather stations examined during the fodder harvest period was well in excess of the mean for the previous thirty years for those stations. In fact, the mean rainfall in the month of May was almost double the 30-year mean for that month. During the grain harvest, the rainfall figures dropped dramatically to two-thirds of the yearly mean in August and then to a quarter of the yearly mean in September. On collating these facts with the literature, a fodder crop with high fungal activity and a grain crop with less fungal activity can be predicted. The variance between the two hays and the haylage were quite significant. Of the sixty-three Canadian hays sampled, only eight (13\%) contained pathogenic fungi. Of the eight positives, $50 \%$ were A. fumigatus with the remaining fifty divided between $A$. niger and A. flavus. No Fusarium was isolated. The Irish hay did not fare as well. Thirty-one (50\%) of the sixty-two Irish hays sampled contained pathogenic fungi. No Fusarium was isolated: all were Aspergillus, including A. fumigatus, A. niger and $A$. flavus. The haylage proved superior to the Irish hay but not as good as the Canadian hay. Twenty of the fiftyfour sampled contained pathogenic fungi with Aspergillus fumigatus accounting for $80 \%$ of the positives. Again, no Fusarium was isolated. A number of points arise from this data. Firstly, the excessive rainfall during the fodder harvest in Ireland has contributed to the production of hay of which $50 \%$ contains pathogenic fungi. Compare this to the Canadian hay which contained $13 \%$ positives - this hay was produced in a much drier climate which has an overall 25-30\% lower humidity during forage harvest periods as compared to Ireland. No Fusarium was isolated from forage which would suggest either none existed pre-harvest, or that Aspergillus propagated during storage.

The haylage showed superior results than the Irish hay at $37 \%$ positive, but it was still a very high figure. Of the positives, $80 \%$ contained Aspergillus fumigatus which complements the characteristic that this particular strain can survive oxygen depletion.

The results of the concentrated feed fungal analysis present a much different picture. Thirty-eight coarse mixes were sampled, of which five (13\%) contained pathogenic fungi. Two contained A. niger, two A. flavus and one sample contained Fusarium. Twenty-six oat samples were tested with only two or $8 \%$ containing pathogenic fungi, $50 \%$ being $A$. niger and $50 \%$ being $A$. flavus. Of the fifty-one pelleted feed samples, only two, or 4\%, contained pathogenic fungi - both Aspergillus flavus. More interestingly, the below-average rainfall seems to have contributed to a low fungal load as compared to the forage harvest. The coarse mix contained the highest percentage. The oats were next, with the pelleted feed containing the least 
amount of pathogenic fungi. This would suggest that the heat treatment pelleted feed undergoes decreased the fungal load. No Aspergillus fumigatus was isolated but one coarse mix contained Fusarium. The weather at the time of harvest, coupled with good storage conditions, have contributed to concentrated feed in 2002 with a relatively low fungal load.

The literature states that zearalenone is produced by Fusaria spp. Only one sample contained Fusarium yet all the different types of feed and forage except oats contained zearalenone above the recommended level (Canadian hay $8 \%$, Irish hay $21 \%$, haylage $8 \%$, coarse mix $6 \%$ and pelleted feed $16 \%$ ). The Irish hay again was the worst in this regard. Five of the nine positives also contained Aspergillus species. This would suggest that Fusarium existed in both crops and forage pre-harvest, died off and produced zearalenone in doing so, with Aspergillus taking over as a storage fungi in some cases. Osweiller (1996) described zearalenone concentration in US hay as rarely, if ever, occurring. This is not the case in Ireland where $21 \%$ contained zearalenone above the recommended levels. None of the oats contained zearalenone, which suggests some of the other ingredients involved in production of the pelleted feed and coarse mix were responsible for the zearalenone contamination.

Fumonisin is also produced by Fusarium yet no samples tested contained this toxin, except in the case of $6 \%$ of the coarse mixes. Again, as the oats were negative, one of the other ingredients is responsible for the contamination. None of the feedstuffs tested positive for ochratoxin except for coarse mix, where $6 \%$ of the samples contained this toxin above the recommended level. Ochratoxin is produced by the toxigenic strains of Aspergillu ochraceus and Penicillium viridicatum, neither of which were isolated during the study. Aflatoxin is produced by Aspergillus flavus and Aspergillus parasiticus. The latter was not isolated during this study. Aspergillus flavus, however, was isolated on seventeen occasions throughout the study yet none of those samples contained aflatoxin above the legal/recommended levels. This would suggest that the production of the feeds and fodders did not stress the fungi sufficiently to release the toxin, nor did the fungi reach sporulation stage. $\mathrm{T} 2$ toxin is a trichothecene produced by Fusarium. It was not detected in any of the fodder samples tested. However, $14 \%$ of the coarse mix, $40 \%$ of the oats and $54 \%$ of the pelleted feeds tested contained T2 toxin above the recommended levels. This suggests that Fusarium was present pre-harvest and a combination of dry weather and production processes removed the fungi, but the fungi produced significant amounts of toxin which remained stable during production and storage. Another theory to add to this may be that the very moist weather early in the summer may have increased Fusarium growth. The dry spell which followed this may have aided the demise of the fungi resulting in a mass of toxin being produced.

\section{Conclusions}

Moulds and mycotoxins are a cause of health problems in horses and other animal species. The results of our paper show that levels of pathogenic fungi and mycotoxins are present in animal feedstuffs. Legislation is currently being drafted at EU level to address the problem of mycotoxins in animal feeds. To date, legislation only covers aflatoxins. The new legislation will cover a range of mycotoxins with acceptable levels that will need to be adhered to. Feed companies will need to have a mycotoxin screening programme on all the ingredients that make up their products. Shelf-life studies may also need to be put in place to ensure that no deterioration in feed occurs.

\section{References}

Clarke, A. (2001). Mycotoxins and their implications in the diet of performance horses. Proceedings of the 17th Equine Nutrition and Physiology Symposium. pp 1- 4.

Diekman, M.A. and Green, M.L. (1992). Mycotoxins and reproduction in domestic livestock. Journal of Animal Science 70: 1615-1627.

Jacobsen, B. J., Bowen, K. L., Shelby, R. A., Deiner, U. L., and Kenuppainen, B. W. (1999). Mycotoxins and Mycotoxicoses. Alabama A\&M and Aubur Universities.

Long, G.G., Diekman, M.A., Tuite, J.F., Shannon, G.M. and Vesonder, R.F. (1983). Effect of Fusarium roseum on pregnancy and the estrous cycle in gilts fed molded corn on day 7-17 post-oestrous. Veterinary Research Communications 6 (3): 199-204.

Murphy, D.S. (1991). Farm respiratory hazards. Fact Sheet Safety 26. Pennsylvania State University.

Osweiler, G. D. (1996). Toxicology. In: The Five Minute Veterinary Consult. Williams and Wilkins. pp 409-432.

Quinn, P. J., Markey, B. K., Carter, M. E., Donnelly, W. 1., and Leonard, F. C. (2002). Mycotoxins and Mycotoxicoses. In: Veterinary Microbiology and Microbial Diseases. Blackwell Science Ltd. pp 229-266.

Smith, J. E., Solomons, G. L., Lewis, C. W. and Anderson, J. G. (1994).

Mycotoxins in Human Nutrition and Health. European Commission Study. Directorate-General XII, Science, Research and Development, Agro-Industrial Research Division.

Smith, T.K., McMillan, E.G. and Castillo, J.B. (1997). Effect of feeding blends of Fusarium mycotoxin-contaminated grains containing DON and fusaric acid on growth and feed consumption of immature swine. Journal of Animal Science 75: 2184-2191.

US Food and Drug Administration. (2001). Guidance for industry - Fumonisin levels in human foods and animal feeds. (Final Guidance). [Online]. Available from: <http://www.cfsan.fda.gov/ dms/fumongu2. html>

Whitlow, L.W. and Haglar, W.M. (2002). Mycotoxins in feeds. Feedstuffs 74: $1-10$. 